\title{
INFECCIÓN POR STRONGYLOIDES STERCORALIS: METANÁLISIS SOBRE EVALUACIÓN DE MÉTODOS DIAGNÓSTICOS CONVENCIONALES (1980-2013)
}

\author{
Laura Campo Polanco (1), Lina A Gutiérrez (1) y Jaiberth Cardona Arias (2).
}

(1) Grupo Biología de Sistemas. Escuela de Ciencias de la Salud. Facultad de Medicina. Universidad Pontificia Bolivariana. Medellín. Colombia.

(2) Grupo de Investigación Salud y Sostenibilidad. Escuela de Microbiología. Universidad de Antioquia.Medellín. Colombia.

$\left(^{*}\right)$ El presente trabajo es un producto derivado del desarrollo de la propuesta de investigación "Diagnóstico molecular de Estrongiloidiasis mediante PCR en tiempo rea. Comparación con métodos de diagnóstico tradicionales" aprobado por el Centro de Investigación para el Desarrollo y la Innovación (CIDI), Universidad Pontificia Bolivariana. Medellín. Colombia en la convocatoria XIV. código interno de radicado 175-11/11 935A.

Sin conflicto de intereses

\section{RESUMEN}

Fundamentos: Las investigaciones sobre los métodos diagnósticos de estrongiloidiasis presentan divergencias en su validez y son incompletas al no reportar datos sobre seguridad, eficiencia y desempeño diagnóstico. El objetivo del trabajo fue evaluar la validez, desempeño, eficiencia y seguridad diagnósticas de cuatro métodos parasitológicos convencionales para la detección de la infección por Strongyloides stercoralis.

Métodos: Revisión sistemática con metanálisis, búsqueda exhaustiva y reproducible de literatura en seis bases de datos para el período 19802013. Se evaluó la calidad de los artículos y se realizó metanálisis con el modelo de efectos aleatorios, calculando sensibilidad, especificidad, cocientes de probabilidad, valores predictivos, proporción de resultados falsos, exactitud, razón de odds, índice J de Youden y curva ROC, usando Meta-DiSc(es) y Epidat 3.1.

Resultados: Se incluyeron 11 estudios con 9.025 individuos. La sensibilidad del método de Baermann fue del $72 \%$, cociente de probabilidad positivo $(\mathrm{CP}+) 228$ y cociente de probabilidad negativo (CP-) 0,32 . El en placa de ágar (CPA) presentó una sensibilidad de $89 \%, \mathrm{CP}+341$ y CP0,11 . En el examen directo en heces la sensibilidad fue del $21 \%$; el CP+ 67 y el CP- 0,67. La sensibilidad de la concentración formol-éter fue del $48 \%$, el CP+ 110 y el CP- 0,59. Áreas bajo la curva ROC de 0,999 en Baermann y CPA; 0,977 en el examen directo en heces y 0,829 en concentración formol-éter; la especificidad fue de $100 \%$ en todas las pruebas.

Conclusiones: Los cuatro métodos parasitológicos convencionales evaluados en este estudio para la detección de $S$. stercoralis pueden ser útiles, sin embargo, resulta más idóneo implementar el en placa de ágar y el método de Baermann.

Palabras clave: Strongyloides stercoralis. Estrongiloidiasis. Diagnóstico. Validez. Seguridad. Eficiencia. Evaluación.

$\overline{\text { Correspondencia }}$

Laura Francisca Campo Polanco

Universidad Pontificia Bolivariana

Calle $78 \mathrm{~B} \mathrm{~N}^{\circ} 72 \mathrm{~A}-109$

Medellin. Colombia

laura.campolanco@gmail.com

\section{ABSTRACT \\ Diagnosis of Strongyloides Stercoralis Infection. Meta-analysis on Evaluation of Conventional Parasitological Methods (1980-2013)}

Background: Research on diagnostic methods have strongyloidiasis divergent validity and incomplete by not reporting data on safety, efficiency and performance diagnosis. Objective: To assess validity, performance, efficiency and safety of four diagnostic conventional parasitological methods for detection of Strongyloides stercoralis infection in the period 1980-2013.

Methods: Systematic review with meta-analysis, exhaustive and reproducible literature search of six databases. Quality of the articles was assessed and meta-analysis was performed under the random effects model, calculating sensitivity, specificity, likelihood ratios, predictive values, proportion of false results, accuracy, odds ratio and Youden index $\mathrm{J}$ and ROC curve using Meta-DiSc(es) and Epidat 3.1.

Results: 11 studies with 9,025 individuals were included. Sensitivity of the Baermann method was $72 \%$, positive likelihood ratio (LR+) 228 and negative likelihood ratio (LR-) 0.32 . The agar plate culture (APC) had a sensitivity of $89 \%$, LR +341 and LR- 0.11 . Stool sensitivity was $21 \%, \mathrm{LR}+$ 67 and LR- 0.67 . Sensitivity of the formol-ether concentration was $48 \%$, LR+ 110 and LR- 0.59. Areas under the ROC curve were 0.999 in Baermann and APC, 0.977 in the stool and 0.829 in formalin-ether concentration; specificity was $100 \%$ in all tests.

Conclusion: The four conventional parasitological methods tested in this study to detect $S$. stercoralis can be helpful; however, agar plate culture and Baermann method are best suited.

Keyword: Strongyloides stercoralis. Strongyloidiasis. Diagnostic validity. Safety. Efficiency. Evaluation. 


\section{INTRODUCCIÓN}

La estrongiloidiasis es una infección parasitaria ocasionada por el nemátodo intestinal Strongyloides stercoralis ${ }^{1}$ que afecta entre 30 y 100 millones personas en el mundo ${ }^{2}$, alcanzando su mayor prevalencia en países tropicales y subtropicales, donde se estima que puede infectar entre el $10 \%$ y el $40 \%$ de la población ${ }^{3}$. Esta parasitosis se relaciona con el bajo desarrollo socioeconómico y las deficiencias higiénicas y sanitarias de las regiones donde este parásito se considera endémico ${ }^{4-6}$.

La infección con $S$. stercoralis se adquiere mediante la penetración de la larva de tercer estadio o filariforme a través de la piel, generalmente se limita al intestino y puede tener un curso asintomático o presentar manifestaciones clínicas leves con episodios de diarrea aguda ${ }^{7}$. La complejidad del ciclo biológico del parásito le confiere la capacidad de realizar ciclos de autoinfección en el interior del huésped y permanecer viable por largos periodos de tiempo sin que sea necesario un contacto externo con los estadios infectivos para generar enfermedad cróni$\mathrm{ca}^{8}$, etapa en la cual se dificulta la detección del parásito, debido a que la excreción de larvas se torna escasa, intermitente e irregular ${ }^{9-11}$.

La estrongiloidiasis crónica suele ser asintomática o puede presentarse con sintomatología leve a moderada, que involucra manifestaciones gastrointestinales, pulmonares, cutáneas y eosinofilia ${ }^{12}$. Si el huésped presenta un estado de inmunosupresión pueden desencadenarse diferentes procesos que conllevan al síndrome de hiperinfección, entre los que se encuentran la autoinfección intensa, que frecuentemente genera complicaciones fatales ${ }^{13}$, las alteraciones en la respuesta inmune humoral $\mathrm{y}$, especialmente, la respuesta celular tipo Th2 tienden a reducir los niveles de interleucina 4 y 5 e inmunoglobulina $\mathrm{E}$, lo que conlleva a un fallo en la producción de eosinófilos y a la ineficiencia del sistema inmune en la eliminación de parásitos, así como al estímulo en la maduración de las larvas rhabditiformes a filariformes, provocando su replicación y migración a los pulmones y a otros órganos ${ }^{14,15}$. En la etapa de hiperinfección el diagnóstico es relativamente sencillo, debido a la alta carga parasitaria, pero frecuentemente no es realizado, ya que la inespecificidad de los signos y síntomas dirigen la sospecha hacia otras etiologías ${ }^{10}$.

La detección microscópica de las larvas de $S$. stercoralis en las heces puede realizarse por varios métodos ${ }^{5}$, siendo el examen directo en heces el que se utiliza de manera rutinaria en los laboratorios clínicos, aunque debido a su baja sensibilidad en la detección de este nemátodo, en algunas ocasiones se requieren procedimientos que aumenten la sensibilidad de la prueba, como son el análisis de varias muestras, para aumentar la probabilidad de detección de las larvas ${ }^{16,17}$ o las técnicas de concentración, entre las que se encuentra la técnica de formol-éter, formalina etil acetato y sedimentación espontánea o Hoffman ${ }^{18-20}$. Otras técnicas utilizadas para el diagnóstico de $S$. stercoralis son la técnica de Bearman y el en placa de ágar ${ }^{21}$. Sin embargo, cada una de ellas presenta divergencias en la sensibilidad reportada por diferentes autores, variando entre $30 \%$ y $95 \%{ }^{22-24}$. Otras técnicas, menos utilizadas, son Harada-mori, Ensayos inmunoenzimáticos tipo ELISA e inmunofluorescencia indirecta ${ }^{18,25,26}$. No obstante, la interpretación de estas pruebas exige mayor cuidado debido a que su sensibilidad y especificidad están condicionadas por el tipo de inmunoglobulina que se detecta y la población en la que es utilizada. Además se pueden producir reacciones cruzadas con otros helmintos y no permiten diferenciar entre las 
infecciones actuales y las pasadas ${ }^{2}$. Igualmente, la reacción en cadena de la polimerasa (PCR) también se ha utilizado como método diagnóstico, presentando diferencias en la sensibilidad obtenida en diferentes ensayos ${ }^{27-29}$.

La utilización del método de Baermann y el en placa de ágar ha sido frecuente en el diagnóstico de $S$. stercoralis ${ }^{24,30-32}$ y múltiples estudios han comparado su utilidad diagnóstica y la de otros métodos, como el examen directo en heces y la concentración formol-éter ${ }^{33}$. La mayoría de las investigaciones solo evalúan la validez diagnóstica en términos de sensibilidad y especificidad del método, lo que resulta limitado en la medida en que estos parámetros no son suficientes para la toma de decisiones clínicas, al obstar otros criterios relevantes en la evaluación de pruebas diagnósticas, tales como el desempeño, la eficiencia y la seguridad. Es decir, la mayoría de estudios sobre evaluación diagnóstica de S. stercoralis no presentan valores predictivos, la proporción de pacientes correctamente diagnosticados, la proporción de resultados falsos, las razones de verosimilitud, la razón de odds diagnóstica, el índice $\mathrm{J}$ de Youden y las curvas ROC.

Los aspectos descritos justifican la realización de un metanálisis que permita analizar los resultados de artículos que aborden este tema, mediante una metodología con criterios claros para la selección y recolección de la información, disminuyendo los sesgos de selección y de extracción, y aumentando la precisión, la potencia y la validez externa de las conclusiones $^{34,35}$.

El objetivo de la investigación fue evaluar la validez, el desempeño, la exactitud y la seguridad diagnósticas de cuatro métodos parasitológicos convencionales para la detección de la infección por $S$. stercoralis en el periodo 1980-2013.

\section{MATERIAL Y MÉTODOS}

Tipo de estudio. Revisión sistemática de la literatura con metanálisis.

Búsqueda de información. Se incluyeron artículos originales publicados entre 1980 y 2013 que incluyeran los términos de búsqueda en el título y el resumen, que abordaran el diagnóstico de Strongyloides stercoralis en humanos, en los que se reportara la sensibilidad y especificidad de las pruebas de diagnóstico Baermann, en placa de ágar, examen directo en heces y la concentración formol-éter, que estuvieran registrados en las bases de datos PubMed, ScienceDirect, EMBASE, LILACS, Scielo y OVID (Global health y Ovid Medline). Se realizó una búsqueda exhaustiva en las bases de datos mencionadas y en la Biblioteca Cochrane para revisiones sistemáticas (EBM Reviews-Cochrane Database of Systematic Reviews), empleando los siguientes términos en título y resumen: [Strongyloides stercoralis y diagnóstico] y [Estrongiloidiasis y diagnóstico y sus equivalentes] que estuvieran escritos en inglés o portugués, divididas en dos rutas de búsqueda diferentes: Strongyloides stercoralis AND diagnosis y Strongyloidiasis AND diagnosis. Se realizó una búsqueda inicial sin la aplicación de ningún filtro con el fin de establecer el número total de resultados identificados en la diferentes bases de datos. Posteriormente se aplicaron los filtros disponibles para cada una de las bases de datos y el total de referencias encontradas fueron exportadas al programa EndNote Web (Thomson Reuters) para la eliminación de duplicados.

Criterios de inclusión: estudios observacionales publicados entre los años 1980 y 2013 donde se reportara la sensibilidad y especificidad de las pruebas de diagnóstico Baermann, en placa de ágar, examen directo en heces y la concentración formol-éter y que especificaran el protocolo de ejecución de las técnicas diagnósticas. 
Criterios de exclusión: no se incluyeron los artículos que evaluaban pruebas diferentes a las convencionales para diagnóstico de $S$. stecoralis, los que presentaron problemas de validez interna o externa por no controlar sesgos de información y selección, los que no hubiesen realizado cegamiento entre evaluaciones o que no definieron la prueba de referencia. De esta manera se controló el sesgo de cada estudio individual. Para determinar la calidad de los estudios elegibles se emplearon los criterios de la guía QUADAS (Quality Assessment of Diagnostic Accuracy Studies) ${ }^{36}$ y se seleccionaron específicamente los que cumplían 10 o más de los 14 ítems estipulados. Con esto se garantizó una elevada calidad metodológica, por lo que no fue necesario hacer análisis por subgrupos según el grado de calidad metodológica de los estudios individuales.

Asimismo se determinaron las variables a analizar en cada estudio: i) Lugar de estudio; ii) Tipo de población; iii) Edad de los participantes en el estudio; iv) Técnica evaluada; v) Prueba o pruebas de referencia empleadas; vi) Número de sujetos estudiados clasificados en verdaderos positivos (individuos con la infección que presentan un resultado positivo); vii) Número de sujetos estudiados clasificados como falsos positivos (individuos sin la infección que presentan un resultado positivo); viii) Número de sujetos estudiados clasificados como falsos negativos (individuos con la infección que presentan un resultado negativo); ix) Número de sujetos estudiados clasificados como verdaderos negativos (individuos sin la infección que presentan un resultado negativo). Para la extracción de la información se diseñó una hoja de cálculo en formato Excel (Microsoft Office) la cual fue diligenciada independientemente por dos investigadores, para garantizar la reproducibilidad en la extracción de los datos.
Recolección de la información. Se realizó una búsqueda por sensibilidad, realizando una inicial sin límites y posteriormente aplicando los filtros propios de cada base de datos para disminuir la cantidad de artículos identificados que se podría importar desde el programa EndNoteweb para la eliminación de duplicados, para obtener el mayor número de estudios posibles indizados en las bases de datos bibliográficas y garantizar la exhaustividad del protocolo de investigación efectuado.

La recolección de la información la realizaron dos investigadores de forma independiente para garantizar la reproducibilidad de los resultados y la selección de los artículos. Las discrepancias se resolvieron por consenso.

Los estudios que cumplían los criterios de inclusión fueron leídos en su totalidad para determinar el número de investigaciones que se incluirían en la síntesis cualitativa y cuantitativa, posterior a la aplicación de los criterios de exclusión. De los manuscritos incluidos se realizó la extracción de información sobre lugar de estudio, tipo de población, edad, técnica evaluada, prueba o pruebas de referencia y número de sujetos estudiados clasificados en verdaderos positivos, falsos positivos, falsos negativos y verdaderos negativos. Dicha extracción se realizó con base en una hoja de registro estandarizada en Excel, diligenciada por dos investigadores de forma independiente, la cual se evaluó con índices kappa de 1,00 para las variables cualitativas y coeficiente de correlación intraclase de 1,00 para las cuantitativas.

Análisis de la información. La validez de las cuatro pruebas se evaluó con la sensibilidad, la especificidad y las razones de verosimilitud o cocientes de probabilidad (CP), los cuales se interpretaron con base en las siguientes categorías: i) excelente 
ayuda en el diagnóstico: $\mathrm{CP}-<0,1$ y $\mathrm{CP}+$ $>10$; ii) buena ayuda diagnóstica o de importancia clínica: CP- entre 0,1-0,2 y $\mathrm{CP}+5-10$; iii) poca ayuda al clínico: $\mathrm{CP}-$ entre 0,21 y $0,5 \mathrm{CP}+$ entre 2 y 5 y iv) la prueba no presentaba capacidad discriminante para $\mathrm{CP}$ - entre 0,51 y 1 o $\mathrm{CP}+$ entre $1 \mathrm{y} 2$. Adicionalmente se realizaron curvas Receiver Operating Characteristic (ROC) para calcular el área bajo la curva de cada técnica, usando la constante del modelo de Moses y el modelo mínimos cuadrados no ponderados. Se categorizó como buena para valores entre 0,75 y 0,89 ; muy buena entre 0,90 y 0,95 y excelente a partir de 0,96. El desempeño de los métodos parasitológicos se estimó a partir del análisis de los valores predictivos y la proporción de resultados falsos. La información relacionada con los positivos verdaderos y falsos y los negativos verdaderos y falsos fueron almacenados y analizados en una base de datos en el software Meta-analysis of studies of evaluations of Diagnostic and Screening tests Meta-DiSc(es). Se empleó el método de aglomeración con el estadístico Prueba Q $\left(\mathrm{chi}^{2}\right)$ de DerSimonian-Laird (REM), se agregó 0,5 a las celdas con cero, se calcularon los intervalos de confianza del $95 \%$ con corrección por sobredispersión. La eficiencia o exactitud se estimó mediante la evaluación del porcentaje de pacientes correctamente diagnosticados y la Razón de Odds Diagnóstica (ORD) (tomándola como de pésima utilidad para valores cercanos a 1,0 y de excelente utilidad para discriminar a los sujetos sanos de los infectados con valores mayores a 100). Mientras que para valorar el rendimiento de la prueba se estimó el Índice J de Youden (se calificaron como excelentes los valores cercanos a 1,0). En todos los parámetros se calcularon intervalos de confianza del $95 \%$.

Se determinó la heterogeneidad u homogeneidad de los metanálisis de cada parámetro de la evaluación diagnóstica a través del estadístico Q de Cochran que sigue una distribución chi $^{2}$ y para el análisis de sensibilidad se estableció el porcentaje de peso de cada estudio individual sobre el resultado global del $\mathrm{CP}+, \mathrm{CP}-\mathrm{y}$ ORD. Además, en el software MetaDiSc(es) se realizaron los Forest Plot para la sensibilidad, especificidad, $\mathrm{CP}+, \mathrm{CP}-\mathrm{y}$ ORD de las pruebas identificadas, como resultado total del metanálisis para evidenciar efectos individuales y el efecto global, con sus respectivos intervalos de confianza. Se debe precisar que el MetaDiSc(es) no presenta los resultados relacionados con los valores predictivos, la proporción de resultados falsos, el porcentaje de pacientes correctamente diagnosticados ni el índice J de Youden, por lo que estos parámetros, con sus respectivos intervalos de confianza, fueron calculados con el Programa para análisis Epidemiológico de Datos Tabulados de la Organización Panamericana de la Salud (EPIDAT) versión 3.1, tanto para los estudios individuales como para el resultado global de las pruebas analizadas. En todos los análisis se tomó una significación estadística de 0,05 .

\section{RESULTADOS}

En la búsqueda inicial se identificaron 12.863 publicaciones, las cuales se redujeron a 2.001 a partir de la aplicación de criterios como la temporalidad y la inclusión de términos de búsqueda en título y resumen. De ellos 1.028 eran duplicados. 973 artículos fueron sometidos a evaluación del resumen y 18 artículos fueron seleccionados para la evaluación del texto completo. Finalmente, después de aplicar los criterios de la guía QUADAS, se obtuvo un total de 11 artículos que fueron incluidos en el metanálisis (tabla 1). El $64 \%$ de los estudios (7/11) se realizó en América y de estos 5 fueron realizados en Suramérica. Los trabajos incluían personas de todas las edades en un rango entre 1 y 86 años, 6 estudios procedían de 
Figura 1

Algoritmo de selección de los artículos
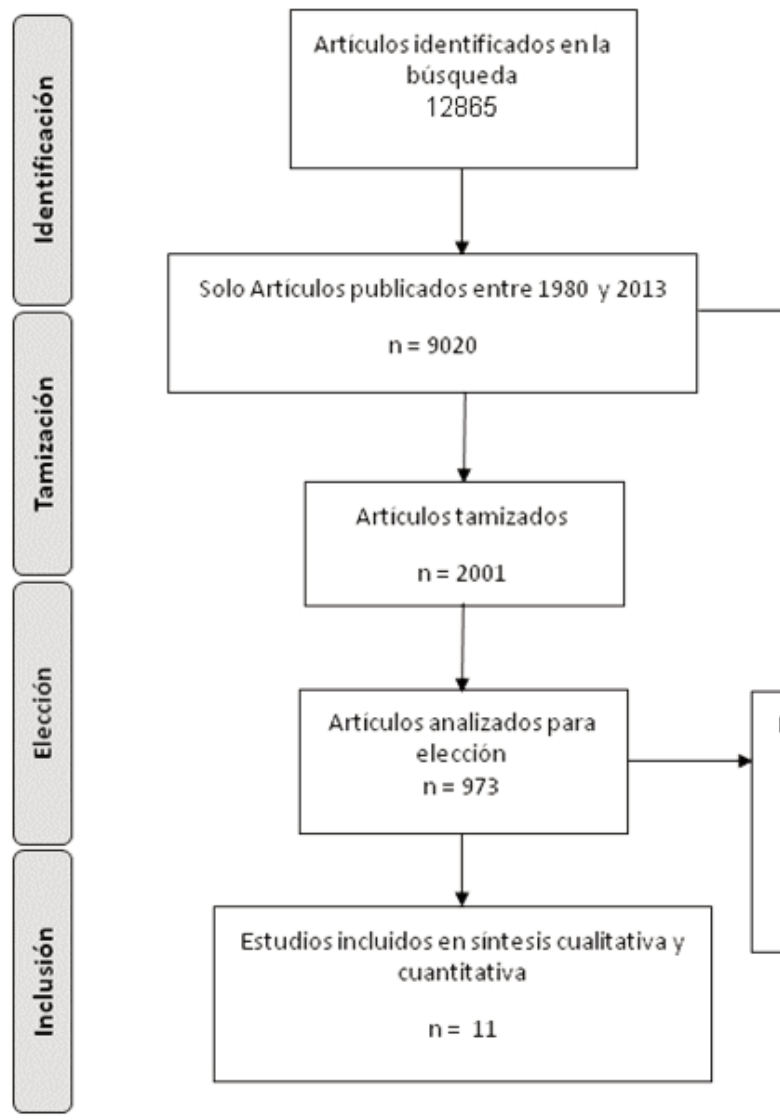

Notiene términos de búsqueda en titulo $y /$ o resumen $n=7019$

Articulos duplicados $n=1028$
Reportes de caso o revisiones $n=751$

Evaluaciones diferentes a métodos convencionales y datos incompletos $n=205$

Porprotocolo $n=6$ población general. Los 5 estudios restantes incluían niños, población indígena, individuos con eosinofilia periférica y personas que presentaban diferentes condiciones de base que podían predisponer a la estrongiloidiasis. Un ejemplo de ello era un estudio que se realizó en personas con VIH/SIDA ${ }^{37}$ y otro en personas alcohólicas $^{38}$ (tabla 2).

En ningún estudio se empleó una única técnica como prueba de referencia sino una combinación de métodos diagnósti- cos para identificar a los individuos infectados por parásitos intestinales y a los no infectados. El metanálisis se realizó para un total de 9.025 individuos. En 2.459 $(27,2 \%)$ se evaluó el método de Baermann, en $1.556(17,2 \%)$ el examen directo en heces, en $3.563(39,5 \%)$ el método diagnóstico utilizado fue en placa de ágar $y$ en $1.447(16 \%)$ concentración formoléter. El total de personas infectadas fue de 1.479 sujetos $(16,4 \%)$ y el de personas $\sin$ parasitismo intestinal de $7.546(83,6 \%)$ mientras que el número de personas sin 
Tabla 1

Frecuencia de artículos hallados mediante la aplicación del protocolo de investigación

\begin{tabular}{|c|c|c|c|}
\hline \multirow[b]{2}{*}{ Fuente } & \multicolumn{3}{|c|}{ Términos de búsqueda } \\
\hline & $\begin{array}{c}\text { Strongyloides } \\
\text { stercoralis } \\
\text { AND } \\
\text { diagnosis }\end{array}$ & $\begin{array}{c}\text { Strongyloidiasis } \\
\text { AND } \\
\text { diagnosis }\end{array}$ & Total \\
\hline PubMed & & & \multirow{6}{*}{67} \\
\hline Sin límite & 998 & 1.773 & \\
\hline Humanos & 905 & 1.399 & \\
\hline Texto completo gratis & 221 & 254 & \\
\hline Límite de tiempo & 216 & 235 & \\
\hline Título y resumen & 33 & 34 & \\
\hline Embase & & & \multirow{4}{*}{718} \\
\hline Sin límite & 1.459 & 1.783 & \\
\hline Año de publicación & 947 & 1.034 & \\
\hline Solo artículos & 357 & 361 & \\
\hline ScienceDirect & & & \multirow{4}{*}{70} \\
\hline Sin límite & 1.767 & 1453 & \\
\hline Revista & 1.389 & 1147 & \\
\hline Título y resumen & 34 & 36 & \\
\hline OVID & & & \multirow{5}{*}{856} \\
\hline Sin límite & 1.546 & 1.794 & \\
\hline Año de publicación & 1.456 & 1.622 & \\
\hline Solo artículos & 1.381 & 1.521 & \\
\hline Texto completo & 391 & 465 & \\
\hline LILACS & & & \multirow{2}{*}{221} \\
\hline Sin límite & 120 & 101 & \\
\hline \multirow[t]{2}{*}{ Scielo } & & & \multirow{2}{*}{69} \\
\hline & 40 & 29 & \\
\hline Total & & 12.683 & 2.001 \\
\hline Sin duplicados & & 973 & \\
\hline
\end{tabular}

parasitismo intestinal con cada uno de los métodos fue 2.094 con Baermann, 1.245 con examen directo en heces, 3.029 con en placa de ágar y 1.178 en concentración formol-éter (tabla 3).

Al analizar el porcentaje de peso de cada estudio mediante la evaluación de los cocientes de probabilidad y las razones de odds diagnósticas se observó que en los estudios que evaluaron el método de Baermann se halló un porcentaje similar para los cocientes de probabilidad positivos, sin embargo, en los cocientes de probabilidad negativos y la ROD se encontró una variación en los datos correspondientes a estos estimativos.

En el metanálisis de la sensibilidad se obtuvo una medida global del $72 \%$ (IC $95 \%=67 \%-76 \%$ ) para el método de Baermann, del 89\% (IC 95\%=86\%-92\%) para en placa de ágar, del $21 \%$ (IC 95\%=16\%$26 \%$ ) en el examen directo en heces y del $48 \%$ (IC $95 \%=42 \%-54 \%$ ) en formol-éter. Con todos los métodos hubo heterogeneidad entre los estudios incluidos (figura 2). En los cuatro métodos diagnósticos la especificidad fue del $100 \%$.

El cociente de probabilidad positivo fue 228 (IC 95\%=90-576) en el método de Baermann, 341 (IC 95\%=142-818) en el en placa de ágar, 67 (IC 95\%=19-239) en el examen directo en heces y 110 (IC $95 \%=20-604)$ en formol-éter, con resultados homogéneos en los estudios incluidos en la evaluación de las cuatro técnicas (figura 3). Por su parte, el cociente de probabilidad negativo fue 0,32 en el método de Baermann; 0,11 en en placa de ágar; 0,67 en el examen directo en heces y 0,59 en formol-éter, con hallazgos heterogéneos en cada una de las técnicas evaluadas (figura 4).

Las áreas bajo las curvas ROC halladas fueron 0,999 en los métodos de Baermann y en placa de ágar; 0,977 en el examen directo en heces y 0,829 en formol-éter (figura 5).

La ROD fue de 928 en el método de Baermann, 3.489 en el en placa de ágar, 111 en el examen directo en heces y 196 en la concentración formol-éter (tabla 4), con resultados que evidencian la homogeneidad entre los estudios individuales que evaluaron cada una de las técnicas ( $p$ Cochran $\mathrm{Q}>0,05)$.

En cuanto a la evaluación de parámetros como el desempeño, la eficiencia y la seguridad de cada uno de los cuatro méto- 
Tabla 2

Descripción de los estudios analizados para los cuatro métodos parasitológicos convencionales para la detección de la infección por $S$. stercoralis en el periodo 1980-2013

\begin{tabular}{|c|c|c|c|c|}
\hline Autor & Año & País & Población & Rango de edad \\
\hline \multicolumn{5}{|c|}{ Método de Baermann } \\
\hline Catarinella $\mathrm{G}^{38}$ & 1989 & Costa Rica & Alcohólicos & Adultos \\
\hline Figuera $\mathrm{L}^{53}$ & 2002 & Venezuela & General & $1-50$ \\
\hline Ribero $Z^{54}$ & 2002 & Venezuela & General & $1-47$ \\
\hline Marchi B ${ }^{37}$ & 2003 & Brasil & Con y sin VIH & $18-40$ \\
\hline Lau C $C^{55}$ & 2005 & Perú & Indígenas & $1-75$ \\
\hline Steinmann $\mathrm{P}^{56}$ & 2007 & China & General & $4-84$ \\
\hline Becker $\mathrm{S}^{57}$ & 2011 & Costa de Marfil & General & $13-75$ \\
\hline Ines $\mathrm{E}^{58}$ & 2011 & Brasil & General & Sin dato \\
\hline Khieu $\mathrm{V}^{59}$ & 2013 & Camboya & Niños & 6-19 \\
\hline \multicolumn{5}{|l|}{ en placa de ágar } \\
\hline Salazar $\mathrm{S}^{60}$ & 1995 & Estados Unidos & Pacientes con eosinofilia & Sin dato \\
\hline Ines $\mathrm{E}^{58}$ & 2011 & Brasil & General & Sin dato \\
\hline Marchi B ${ }^{37}$ & 2003 & Brasil & Con y sin VIH & $18-40$ \\
\hline Becker $S^{57}$ & 2011 & Costa de Marfil & General & $13-75$ \\
\hline Figuera $\mathrm{L}^{53}$ & 2002 & Venezuela & General & $1-50$ \\
\hline Lau $C^{55}$ & 2005 & Perú & Indígenas & $1-75$ \\
\hline Ribero $Z^{54}$ & 2002 & Venezuela & General & $1-47$ \\
\hline Steinmann $\mathrm{P}^{56}$ & 2007 & China & General & $4-84$ \\
\hline Khieu $\mathrm{V}^{59}$ & 2013 & Camboya & Niños & $6-19$ \\
\hline Jongwutiwes $\mathrm{S}^{61}$ & 1999 & Tailandia & General & $5-86$ \\
\hline \multicolumn{5}{|c|}{ Examen directo en heces } \\
\hline Catarinella $\mathrm{G}^{38}$ & 1989 & Costa Rica & Alcohólicos & Adultos \\
\hline Jongwutiwes $\mathrm{S}^{61}$ & 1999 & Tailandia & General & $5-86$ \\
\hline Figuera $\mathrm{L}^{53}$ & 2002 & Venezuela & General & $1-50$ \\
\hline Ribero $Z^{54}$ & 2002 & Venezuela & General & $1-47$ \\
\hline Lau C ${ }^{55}$ & 2005 & Perú & Indígenas & $1-75$ \\
\hline \multicolumn{5}{|c|}{ Concentración formol-éter } \\
\hline Catarinella $\mathrm{G}^{38}$ & 1989 & Costa Rica & Alcohólicos & Adultos \\
\hline Jongwutiwes $\mathrm{S}^{61}$ & 1999 & Tailandia & General & $5-86$ \\
\hline Figuera $\mathrm{L}^{53}$ & 2002 & Venezuela & General & $1-50$ \\
\hline Ribero $Z^{54}$ & 2002 & Venezuela & General & $1-47$ \\
\hline
\end{tabular}

dos parasitológicos convencionales evaluados para la detección de la infección por $S$. stercoralis se hallaron los siguientes valores: i) en el método de Baermann el valor predictivo negativo fue $93 \%$, la proporción de falsos negativos $37 \%$, el porcentaje de pacientes correctamente diagnosticados 93\% y el Índice J de Youden de 0,7 ; ii) El en placa de ágar pre- sentó un valor predictivo negativo de $98 \%$, proporción de falsos negativos $11 \%$, porcentaje de pacientes correctamente diagnosticados $98 \%$ e Índice $\mathrm{J}$ de Youden de 0,9 ; iii) en el examen directo en heces, el valor predictivo negativo observado fue de $83 \%$, la proporción de falsos negativos $79 \%$, el porcentaje de pacientes correctamente diagnosticados 
Tabla 3

Descripción de los valores diagnósticos y el porcentaje de peso de cada estudio en los resultados globales de los cuatro métodos parasitológicos convencionales para la detección de la infección por S. stercoralis

\begin{tabular}{|c|c|c|c|c|c|}
\hline \multirow{2}{*}{ Autor } & \multirow{2}{*}{$\mathbf{V P} /(\mathbf{V P}+\mathbf{F N})$} & \multirow{2}{*}{$\mathbf{V N} /(\mathbf{V N}+\mathbf{F P})$} & \multicolumn{3}{|c|}{ Porcentaje de Peso } \\
\hline & & & $\mathrm{CP}+$ & CP- & ORD \\
\hline \multicolumn{6}{|c|}{ Método de Baermann } \\
\hline Ines $E^{58}$ & $31 / 42$ & $592 / 592$ & 11,1 & 12,6 & 11,9 \\
\hline Marchi B ${ }^{37}$ & $16 / 33$ & $391 / 391$ & 11,0 & 14,3 & 11,9 \\
\hline Becker $S^{57}$ & $26 / 37$ & $255 / 255$ & 11,1 & 12,7 & 11,9 \\
\hline Figuera $\mathrm{L}^{53}$ & $16 / 24$ & $76 / 76$ & 11,1 & 12,0 & 11,6 \\
\hline Lau $C^{55}$ & $25 / 42$ & $67 / 67$ & 11,2 & 14,0 & 12,0 \\
\hline Catarinella $\mathrm{G}^{38}$ & $35 / 36$ & $170 / 170$ & 11,2 & 4,3 & 9,9 \\
\hline Ribero $Z^{54}$ & $7 / 18$ & $38 / 38$ & 10,9 & 13,9 & 11,4 \\
\hline Steinmann $\mathrm{P}^{56}$ & $21 / 21$ & $159 / 159$ & 11,2 & 1,7 & 7,1 \\
\hline Khieu V ${ }^{59}$ & $84 / 112$ & $346 / 346$ & 11,2 & 14,4 & 12,2 \\
\hline \multicolumn{6}{|l|}{ en placa de ágar } \\
\hline Salazar S ${ }^{60}$ & $13 / 14$ & $211 / 211$ & 10,0 & 9,0 & 8,8 \\
\hline Ines $\mathrm{E}^{58}$ & $40 / 42$ & $592 / 592$ & 10,0 & 9,9 & 10,0 \\
\hline Marchi B ${ }^{37}$ & $23 / 33$ & $391 / 391$ & 9,9 & 11,5 & 11,3 \\
\hline Becker $S^{57}$ & $17 / 37$ & $255 / 255$ & 9,9 & 11,7 & 11,5 \\
\hline Figuera $\mathrm{L}^{53}$ & $24 / 24$ & $76 / 76$ & 10,1 & 5,8 & 6,0 \\
\hline Lau $C^{55}$ & $40 / 42$ & $67 / 67$ & 10,1 & 9,9 & 9,9 \\
\hline Ribero $Z^{54}$ & $16 / 18$ & $38 / 38$ & 10,1 & 10,0 & 9,8 \\
\hline Steinmann $\mathrm{P}^{56}$ & $19 / 21$ & $159 / 159$ & 10,0 & 10,0 & 9,9 \\
\hline Khieu $\mathrm{V}^{59}$ & $99 / 112$ & $346 / 346$ & 10,0 & 11,5 & 11,6 \\
\hline Jongwutiwes $\mathrm{S}^{61}$ & $186 / 191$ & $894 / 894$ & 10,0 & 10,8 & 11,1 \\
\hline \multicolumn{6}{|c|}{ Examen directo en heces } \\
\hline Figuera $\mathrm{L}^{53}$ & $13 / 24$ & $76 / 76$ & 20,6 & 15,0 & 20,2 \\
\hline Lau $C^{55}$ & $2 / 42$ & $67 / 67$ & 17,7 & 26,5 & 18,0 \\
\hline Catarinella $\mathrm{G}^{38}$ & $20 / 36$ & $170 / 170$ & 20,7 & 17,2 & 20,8 \\
\hline Ribero $Z^{54}$ & $9 / 18$ & $38 / 38$ & 20,6 & 14,2 & 19,6 \\
\hline Jongwutiwes $\mathrm{S}^{61}$ & $20 / 191$ & $984 / 984$ & 20,4 & 26,9 & 21,3 \\
\hline \multicolumn{6}{|c|}{ Concentración formol-éter } \\
\hline Catarinella $\mathrm{G}^{38}$ & $9 / 36$ & $170 / 170$ & 24,8 & 27,4 & 25,1 \\
\hline Figuera $\mathrm{L}^{53}$ & $5 / 24$ & $76 / 76$ & 24,4 & 27,0 & 24,4 \\
\hline Ribero $Z^{54}$ & $11 / 18$ & $38 / 38$ & 25,4 & 17,6 & 24,4 \\
\hline Jongwutiwes $\mathrm{S}^{61}$ & $104 / 191$ & $894 / 894$ & 25,4 & 28,1 & 26,0 \\
\hline
\end{tabular}

VP: Verdaderos Positivos. FN: Falsos Negativos. VN: Verdaderos Negativos. FP: Falsos Positivos. CP+: Cociente de Probabilidad Positivo. CP-: Cociente de Probabilidad Negativo. ORD: Razón de Odds Diagnóstica.

$84 \%$ y el Índice J de Youden de 0,2, y finalmente iv) en el método de formoléter el valor predictivo negativo fue $89 \%$, proporción de falsos negativos $52 \%$, porcentaje de pacientes correctamente diagnosticados 90\% e Índice $\mathrm{J}$ de Youden de 0,5 (tabla 4). La proporción de falsos positivos fue 0 en todos los estudios y el valor predictivo positivo del $100 \%$, con los siguientes intervalos de confianza: Baermann $85 \%-100 \%$, en placa de ágar $99 \%-100 \%$, examen directo en heces $94 \%-100 \%$ y concentración formol-éter 97\%-100\%. 
Figura 2

Metanálisis de la Sensibilidad de los cuatro métodos parasitológicos convencionales para la detección de la infección por $S$. stercoralis. A. Método de Baerman. B. en placa de ágar. C. Examen directo en heces. D. Concentración formol-éter

A

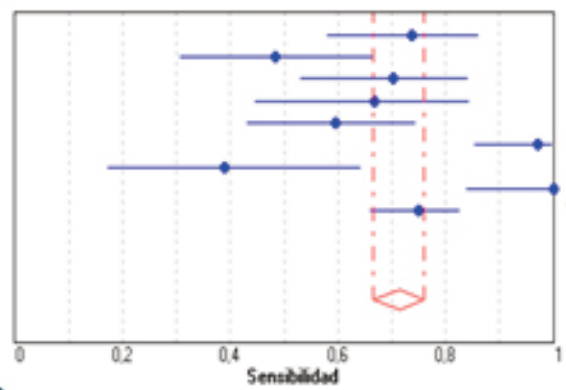

Sensibidad $[95 z a]$

0.74 10.58-0.08

0.43 ip.31-0.65

0.70 .033 .0 .84

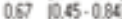

$0.50[0.43 \cdot 0.74]$

0.97 10.85:100

$0.3010 .17-0.54$

$1,00[0,84-1,00$

0.75 [1088-0.83]

B

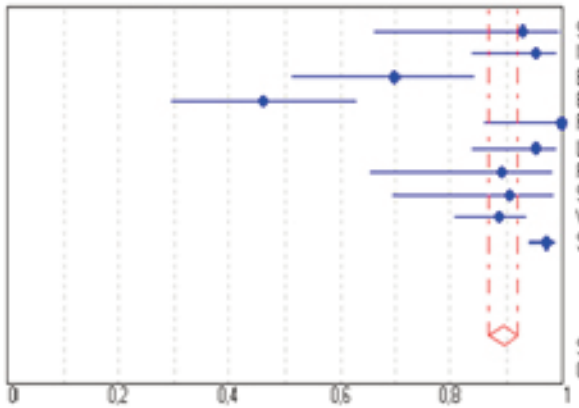

年 Chicustaso $=50, \pi, d=8[0 \cdot 0,0000$

Sensibidad [95\% a]

0.930 .55 .100

0.58 10.84-0.96

0.70 10.51.084

0450.096

100 p pos. 100

0.95 D.8. 09

$080.06 .0 \%$

09070.096

0.88 D.8.0.0.4

097 10.34-0.9:

C

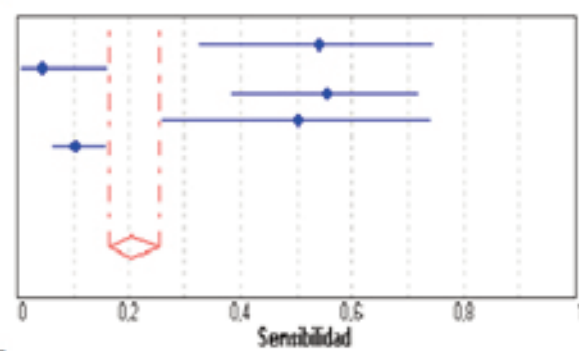

Foved

Lanc

Crsinels

Riseno

Sonchs

Senitadad (95z a)

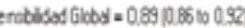

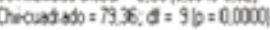

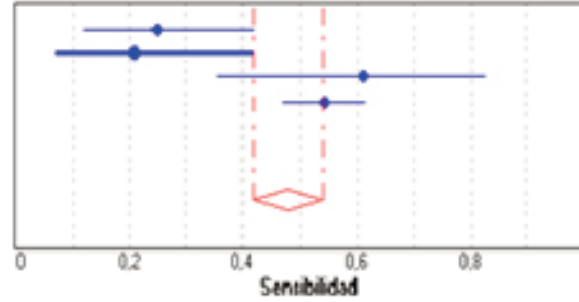

Crainels

fipes:

Rowero

Sonchys

$0.54 \quad 10.32 \cdot 0.74$

$0.0510 .01 \cdot 0.16$

$0.5 \%$ p.20.072

$0.50-0.074$

$0.10 \quad 10.09-0.16$

Seneblids Global $0.21[0.16$ to 0.28

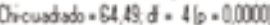

Sentubidad [95\% व]

0.8012 .042

$0.71[0.07 \cdot 0.04$

$0,51[0.56-0.83$

$0.54[0.07-0.82$

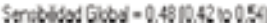

Chrousdodo - 20,00, d * 36 = 0.002 


\section{Figura 3}

Metanálisis de los Cocientes de Probabilidad Positivos de los cuatro métodos parasitológicos convencionales para la detección de la infección por $S$. stercoralis.

A. Método de Baerman. B. en placa de ágar. C. Examen directo en heces. D. Concentración formol-éter

\section{A}
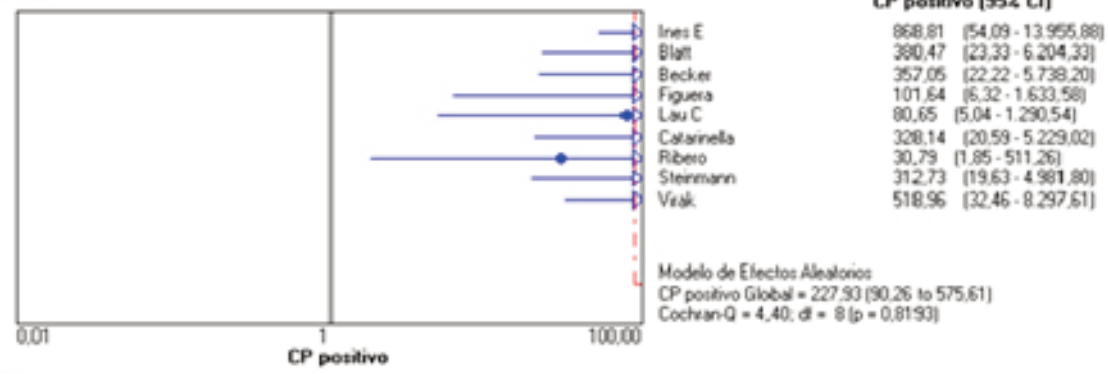

$80.65[5.04-1.290 .54]$

$518.56(32.46-8.29751)$

\$8881 [54.09-1395588]

$300.47 \quad[23.33-6204,33]$

$35705,12222,573801$

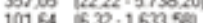

$328.14(20.59-5.229,02)$
$30.79,[1.85-51126)$
$312.73(19.63-4361.80)$

B

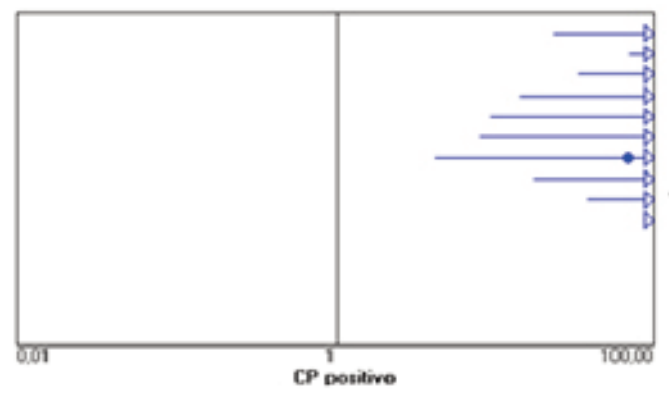

5020

50920

Ineit

Burn

Becker

Fous:

Laic

Steremorn

Soncha

CP positivo [95\% C])

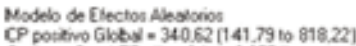

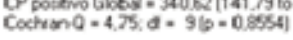

\section{C}

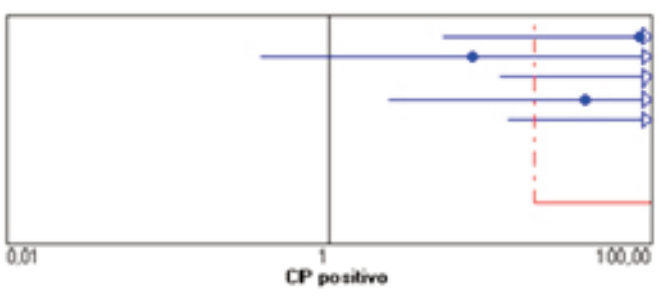

Fovera

Cororinty

Ribeno

Sonchs

CP patitivo (95) C])

$391.60[2382.6112 .27]$

$1.117 .05 \quad 5988 \cdot 17.855 .84$

$541.88[33.65 \cdot 8727.15]$

23579 [14.43 - 3.840.4]

$150.92[9.52-239250]$

$128.09[8.09 \cdot 2029.13]$

$67.74(4.29-106975)$

$283,64[17,75,4533,35]$

611.09
1.738 .72
$[108.27 \cdot 93 \cdot 27.779 .54]$

Modelo de Electos Alewoniof

CP pookivo G lobal $=67,31$ [18.93 to 238,70 ]

Cochrant $=3.35$. $=4$ (p) 0.5010$)$

D

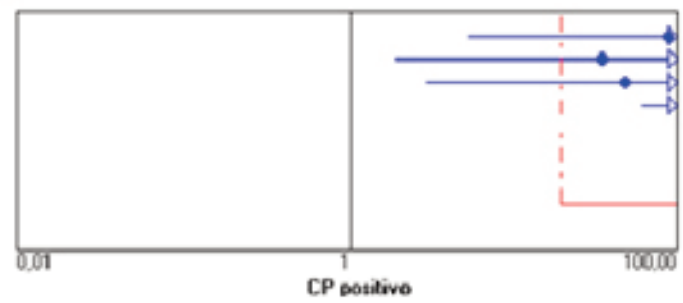

Cotsinel.

Figuela

Ribeno

CP positive (95\% CI)

$83.16[5.13 \cdot 1.349 .05]$

$791 \quad 10,39-16078$

$189,49[11,72 \cdot 3,062.95$

$39.00 \quad[2.39 \cdot 635.25]$

$210.34[12.78 \cdot 3.462 .93$

Sonchs

CP pesitivo (95\% CI)

$87.81 \quad[5.23 \cdot 1.475 .45]$

$3388 \quad[1.94 .591 .42]$

$4721[2.94 \cdot 753.34]$

$974.24(60.90 \cdot 15.610 .91)$

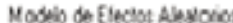

CP poifero Globd = 109,62 (19,89 to 604,32)

Cocturna $0.4,44$ \& $3(p=0.2182)$ 
Figura 4

Metanálisis de los Cocientes de Probabilidad Negativos de los cuatro métodos parasitológicos convencionales para la detección de la infección por $S$. stercoralis.

A. Método de Baerman. B. en placa de ágar. C. Examen directo en heces.

D. Concentración formol-éter

A

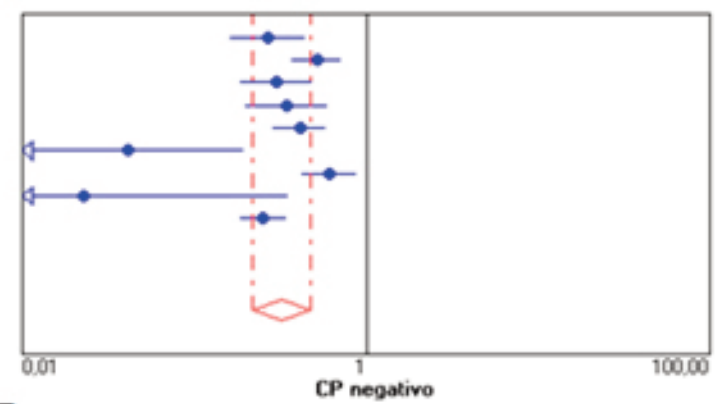

Inet E

Blat

Becket

Figuera

LauC

Carsinels

Ribeto

Steirmym $0.02[0,00.035$

Visk

CP negativo [95 $\mathrm{C}$ ] ]

$0.27[0.16 \cdot 0.44]$

$0.52[0.37 \cdot 0.71]$

$0.30 \quad[0.19 \cdot 0.49$

$0.34[0.20 .0 .59$

$0,41[0,29 \cdot 0,59]$

$0.04[0.01 \cdot 0.19$

$0.25[0.18 \cdot 0.35]$

Modelo de Efectos Alestorion

CP negrivo Gkby $=0.3210 .22$ to 0.47 ,

Cochuon $0=43.35 ; d=8(p=0,0000)$

B

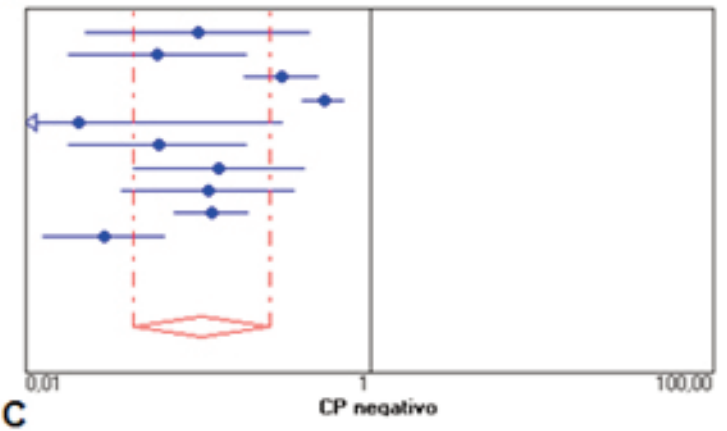

Solazes

Inest $\mathrm{E}$

Blont

Becker

Figuela

LouC

Rbero

Steirmisn

Veat

Sonchs:

CP negativo [95\% C]

$0,10 \quad[0,02 \cdot 0,46]$

$0.06[0.02 \cdot 0.19]$

$0,31 \quad[0,19 \cdot 0,51\}$

$0.54 \quad 10.40 \cdot 0.73)$

$0.02[0,00 \cdot 0,31]$

$0.05 \quad 10.02 \cdot 0.201$

$0,13 \quad 10,04 \cdot 0.42$

$\begin{array}{ll}0,13 & 10,04 \cdot 0,42] \\ 0.11 & 0,04 \cdot 0,37\end{array}$

$0.12(0.07 \cdot 0.20)$

$0.03[0.01 \cdot 0.07]$

Modelo de Ellectos Alearoriot

CP negstivo Global = 0.11 [0.04 to 0.26)

Cochrant $=132.70 ; d=9 / 0=0,0000$

c

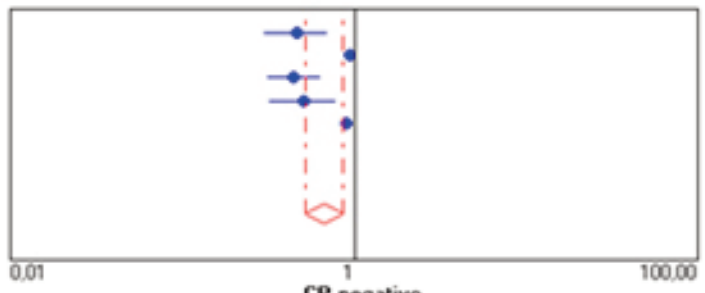

Figuera

Las C

Carainels

Pbeto

CP negativo (95x C.]

Somchy

$0,45 \quad 10,30 \cdot 0,71$

$0.95[0.88-1.02]$

$0.45 \quad[0.31-0.64]$

$0.51 \quad 10.32 \cdot 0.80$

$0.89[0.85 \cdot 0.94]$

Modelo de Efectos Aleyariot

CP negutivo Globs $=0.6710 .53$ to 0.851

Cochan $0-6377$; $=4[0=0.0000)$

D

CP negativo

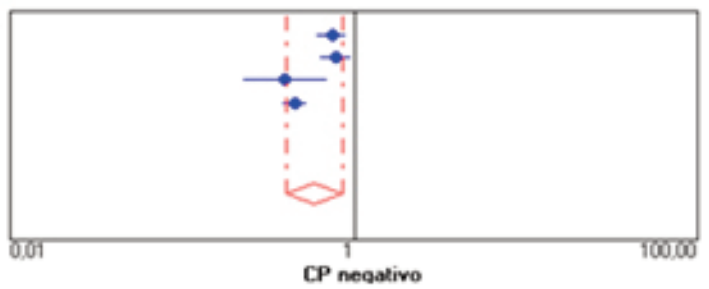

Corrinels

Figuena

Ribero

Sonchs

Modelo de Electos Alestorio:

CP negutivo Globs $=0,5910,41$ to 0.85$)$

Cochant $0=32.25$; $a$ - 3 ip = 0.0000$)$ 


\section{Figura 5}

Metanálisis de las Curvas ROC de los cuatro métodos parasitológicos convencionales para la detección de la infección por $S$. stercoralis. A. Método de Baerman.

B. en placa de Ágar. C. Examen directo en heces; D. Concentración formol-éter A
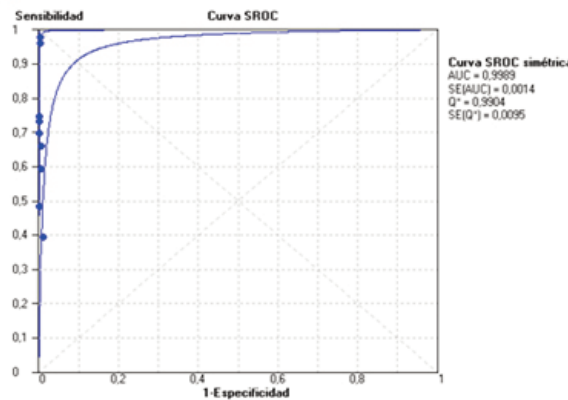

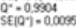

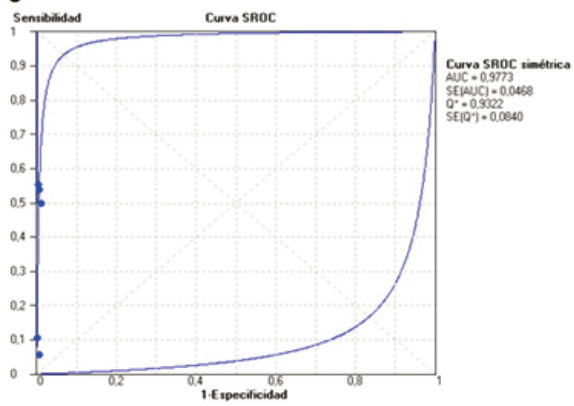

B

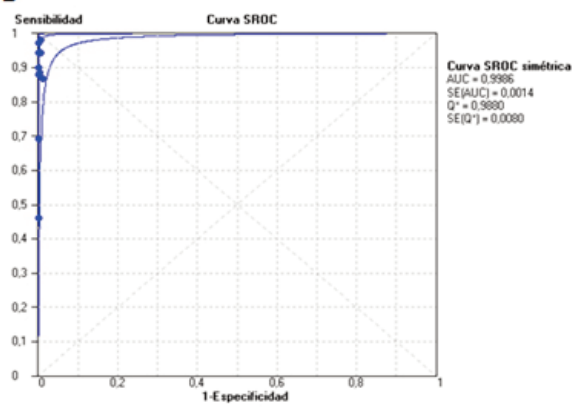

D

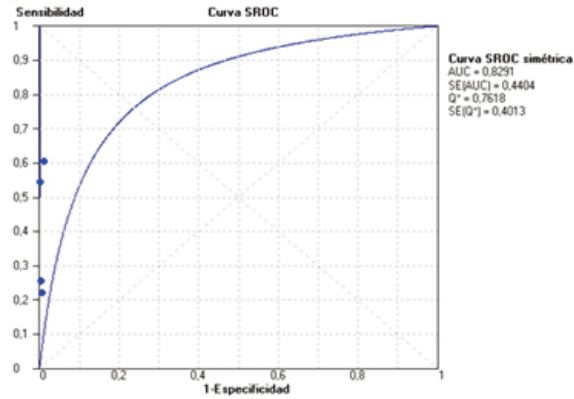


Tabla 4

Evaluación diagnóstica de los cuatro métodos parasitológicos convencionales para la detección de la infección por $S$. stercoralis

\begin{tabular}{|c|c|c|c|c|c|}
\hline Autor & ORD & VPN (IC95\%) & PFN (IC95\%) & PPCD (IC95\%) & $\begin{array}{l}\text { Índice J de } \\
\text { Youden }\end{array}$ \\
\hline \multicolumn{6}{|c|}{ Método de Baermann } \\
\hline Ines $\mathrm{E}^{58}$ & $3.245\left(187 ;>10^{3}\right)$ & $98(97-99)$ & $26(15-41)$ & $98(97-99)$ & 0,7 \\
\hline Marchi B ${ }^{37}$ & $738\left(43 ;>10^{3}\right)$ & $100(81-100)$ & $52(35-68)$ & $96(94-98)$ & 0,5 \\
\hline Becker $S^{57}$ & $1.177\left(68 ;>10^{3}\right)$ & $100(93-98)$ & $96(94-98)$ & $96(94-98)$ & 0,7 \\
\hline Figuera $\mathrm{L}^{53}$ & $297(16 ; 5405)$ & $91(82-95)$ & $33(18-53)$ & $92(85-96)$ & 0,7 \\
\hline Lau $C^{55}$ & $197(11: 3393)$ & $80(70-87)$ & $41(27-56)$ & $84(76-90)$ & 0,6 \\
\hline Catarinella $\mathrm{G}^{38}$ & $8.070\left(322 ;>10^{3}\right)$ & $99(97-100)$ & $2,8(0,5-14)$ & $100(97-100)$ & 1,0 \\
\hline Ribero $Z^{54}$ & $50(3,0 ; 947)$ & $78(64-7)$ & $61(39-80)$ & $80(68-89)$ & 0,4 \\
\hline Steinmann $\mathrm{P}^{56}$ & $1.3717\left(265 ;>10^{3}\right)$ & $100(98-100)$ & $0(0-15)$ & $100(98-100)$ & 1,0 \\
\hline Khieu V ${ }^{59}$ & $2.054\left(124 ;>10^{3}\right)$ & $93(89-95)$ & $25(18-34)$ & $94(91-96)$ & 0,8 \\
\hline Total & $928(298 ; 2894)$ & $93(86-97)$ & $37(27-51)$ & $93(89-96)$ & 0,7 \\
\hline \multicolumn{6}{|l|}{ en placa de ágar } \\
\hline Salazar $\mathrm{S}^{60}$ & $3807\left(148 ;>10^{3}\right)$ & $100(97-100)$ & $7,1(1,3-32)$ & $100(98-100)$ & 0,9 \\
\hline Ines $\mathrm{E}^{58}$ & $19197\left(906->10^{3}\right)$ & 100(99-100) & $4,8(1,3-16)$ & 100(99-100) & 1,0 \\
\hline Marchi B ${ }^{37}$ & $1752\left(99 ;>10^{3}\right)$ & 98(96-99) & $30(17-47)$ & 98(96-99) & 0,7 \\
\hline Becker $S^{57}$ & $436(25 ; 7518)$ & 93(89-95) & $54(38-59)$ & $93(90-96)$ & 0,5 \\
\hline Figuera $\mathrm{L}^{53}$ & $7497\left(145 ;>10^{3}\right)$ & $100(92-100)$ & $0(0-14)$ & $100(96-100)$ & 1,0 \\
\hline Lau $C^{55}$ & $2187\left(102 ;>10^{3}\right)$ & $97(90-99)$ & $4,8(1,3-16)$ & $98(94-100)$ & 1,0 \\
\hline Ribero $Z^{54}$ & $508\left(23 ;>10^{3}\right)$ & $95(84-99)$ & $11(3,1-33)$ & $96(88-99)$ & 0,9 \\
\hline Steinmann $\mathrm{P}^{56}$ & $2488\left(115 ;>10^{3}\right)$ & $99(96-100)$ & $9,5(2,7-30)$ & $99(96-100)$ & 0,9 \\
\hline Khieu V ${ }^{59}$ & $5107\left(301 ;>10^{3}\right)$ & $96(94-98)$ & $12(6,9-17)$ & $97(95-98)$ & 0,9 \\
\hline Jongwutiwes $\mathrm{S}^{61}$ & $60663\left(3340 ;>10^{3}\right)$ & $99(99-100)$ & $2,6(1,1-6)$ & $100(99-100)$ & 1,0 \\
\hline Total & $3489(1325 ; 9185)$ & $98(98-99)$ & $10,7(8-14)$ & 98(98-99) & 0,9 \\
\hline \multicolumn{6}{|c|}{ Examen directo en heces } \\
\hline Figuera $\mathrm{L}^{53}$ & $180(10 ; 3232)$ & $80(80-87)$ & $79(60-91)$ & $81(72-88)$ & 0,2 \\
\hline Lau $\mathrm{C}^{55}$ & $8,3(0,4 ; 178)$ & $63(53-71)$ & $95(84-99)$ & $63(54-72)$ & 0,0 \\
\hline Catarinella $\mathrm{G}^{38}$ & $423(25 ; 7328)$ & $91(87-95)$ & $44(30-60)$ & $92(88-95)$ & 0,6 \\
\hline Ribero $Z^{54}$ & $77(4 ; 1444)$ & $81(68-90)$ & $50(29-71)$ & $84(72-91)$ & 0,5 \\
\hline \multicolumn{6}{|c|}{ Concentración formol-éter } \\
\hline Catarinella $\mathrm{G}^{38}$ & $118(7 ; 2082)$ & $86(81-90)$ & $75(56-86)$ & $87(82-91)$ & 0,3 \\
\hline Figuera $\mathrm{L}^{53}$ & $43(3 ; 814)$ & $80(80-87)$ & $79(60-91)$ & $81(72-88)$ & 0,2 \\
\hline Ribero $Z^{54}$ & $118(6 ; 2227)$ & $84(71 ; 92)$ & $37(20-61)$ & $88(76-94)$ & 0,6 \\
\hline Jongwutiwes $\mathrm{S}^{61}$ & $2137\left(132 ;>10^{3}\right)$ & $91(89-93)$ & $46(39-53)$ & $92(90-94)$ & 0,5 \\
\hline Total & $196(31 ; 1244)$ & $89(88-91)$ & $52(46-58)$ & $90(89-92)$ & 0,5 \\
\hline
\end{tabular}

VPN: Valor Predictivo Negativo. PFN: Proporción de Falsos negativos. PPCD: Proporción de Pacientes Correctamente Diagnosticados. ORD: Razón de Odds Diagnóstica

\section{DISCUSIÓN}

Este metanálisis evidencia que la técnica con mejor validez, desempeño, eficiencia y rendimiento diagnóstico es el en placa de ágar, seguido de la técnica de Baermann. El examen directo en heces presenta los peores resultados con una validez que refleja su baja capacidad para discriminar entre los individuos infectados con $S$. stercoralis de los no infectados, su desempeño fue deficiente y el rendimiento muy bajo. El método de con- 
centración formol-éter presentó una baja sensibilidad, un cociente de probabilidad negativo que pone de manifiesto su baja capacidad para discriminar entre individuos sin infección y los infectados y una elevada proporción de falsos negativos.

Con los datos expuestos se genera evidencia científica de alto grado que indica que entre los cuatro métodos parasitológicos convencionales evaluados para la detección de la infección por $S$. stercoralis, el diagnóstico etiológico se debería realizar preferiblemente con el en placa de ágar o con la técnica de Baermann. A pesar de que el examen directo en heces y el método de concentración formol-éter presentaron valores aceptables para la ORD, el CP positivo, el área bajo la curva ROC y la proporción de pacientes correctamente diagnosticados, no se recomienda su utilización para el diagnóstico, ya que estos parámetros se explican por sus buenos resultados en las personas sin infección (especificidad del $100 \%$ ) pero presentan rendimiento, desempeño y validez diagnóstica bajos.

Cabe aclarar que entre las geohelmintiasis, la estrongiloidiasis es una enfermedad desatendida, debido a que es una infección que se presenta principalmente en las regiones tropicales, en poblaciones de bajos recursos ${ }^{2,4}$ y a que su diagnóstico tiene múltiples dificultades relacionadas con la recolección, conservación y procesamiento de las muestras, así como con la elección acertada de la técnica diagnóstica ${ }^{5,39,40}$. Con respecto a este último tópico, en esta revisión se observó que las limitaciones relacionadas con los métodos que implican la visualización directa del parásito fueron superadas al tomar como prueba de referencia un conjunto de técnicas y métodos que permiten la detección de varias formas parasitarias en forma simultánea o separada.

Uno de los hallazgos centrales de esta investigación radica en la recomendación de la utilización del en placa de ágar como método de elección en el diagnóstico de estrongi- loidiasis, ya que permite la visualización del rastro dejado por el nemátodo sobre la superficie del ágar, luego de depositar en el centro $2-4$ gr de materia fecal $^{24}$. Sin embargo, no se utiliza de manera rutinaria en los laboratorios clínicos debido a que es considerado como un método laborioso que requiere experiencia para su lectura e interpretación, el tiempo de generación de resultados suele ser desfavorable debido a que puede tardar entre 24 y 72 horas para obtener un resultado fiable $e^{7,16,24}$, sumado al bajo costo de los métodos examen directo en heces y de concentración, debido al uso de menos insumos en su elaboración, lo que podría explicar la elevada frecuencia de uso de estas técnicas diagnósticas con una lectura más rápida, aunque se sabe que su utilidad diagnostica es muy baja $^{41}$.

Basado en el número de estudios realizados y el total de individuos incluidos en cada uno, la técnica más empleada para el diagnóstico de estrongiloidiasis en investigaciones sobre este parásito fue el en placa de ágar, seguida por el método de Baermann. Asimismo, el método menos utilizado fue el de concentración formol-éter, lo cual puede deberse a que no se considera una prueba específica para la detección de $S$. stercoralis, aunque es ampliamente utilizada en los laboratorios clínicos para el diagnóstico de las parasitosis intestinales en general ${ }^{42,43}$.

En contraste, el examen directo en heces, es una técnica sencilla y de bajo costo que resulta útil para el diagnóstico rutinario de las parasitosis intestinales ${ }^{44}$. Sin embargo, en la detección de $S$. stercoralis presentó los peores resultados de validez, desempeño, eficiencia y rendimiento, a pesar de que algunos autores refieren que estas propiedades diagnósticas podrían mejorar al tomar mínimamente 7 muestras seriadas ${ }^{5,32}$ y que podría potenciarse su validez diagnostica si se usa de manera conjunta con la implementación de técnicas de concentración como la de formol-éter o la técnica de concentración de formalina- etil- acetato ${ }^{45}$. 
En la actualidad se han desarrollado diferentes pruebas inmunológicas que incluyen ELISA, inmunofluorescia indirecta y métodos de aglutinación, entre otras. Todos presentan diferentes valores de sensibilidad y especificidad en la detección de $S$. stercoralis, esto puede ser debido a la falta de una buena prueba de referencia para comparar los resultados obtenidos con los diferentes métodos utilizados en la evaluación de dichas pruebas. Por ello el empleo del inmunodiagnóstico para la detección de $S$. stercoralis en laboratorios clínicos depende sobre todo de superar las limitaciones presentadas hasta la fecha en este tipo de análisis, que involucra las reacciones cruzadas con otros helmintos y algunos problemas de diferenciación de infecciones pasadas y activas. Sin embargo, se pueden considerar como una buena alternativa para la tamización de la infección por este nemátodo ${ }^{25,26}$.

Es importante resaltar que en la mayoría de los estudios realizados e incluidos en la presente revisión, la evaluación diagnóstica sólo se basó en los parámetros de sensibilidad, especificidad y valores predictivos de la prueba, lo que clínicamente presenta poco valor. Se debe precisar que la sensibilidad y la especificidad permiten estimar la validez de una prueba diagnóstica, debido a que miden propiedades intrínsecas que son independientes de la prevalencia de la enfermedad, pero presentan la limitación de no proporcionar información acerca de la probabilidad de obtener un resultado positivo o negativo concreto, en función de la presencia o no de la enfermedad o, como en este caso, de la prevalencia de infección por el parásito en cada población específica ${ }^{46}$. Por su parte, el análisis de los valores predictivos positivo y negativo muestra información clínicamente relevante en cuanto al diagnóstico, pero tiene la limitación de que dependen de la prevalencia de la infección en la población estudiada ${ }^{47-49}$.

Debido a las limitaciones expuestas con relación a los estudios que se encuentran reportados en la literatura científica, donde se ha valorado los métodos de diagnóstico etiológico de $S$. stercoralis, se hace necesaria la realización de estudios adicionales para evaluar otros parámetros con mayor utilidad clínica. Tal es el caso del cociente de probabilidades, razón de verosimilitudes o razón de probabilidad, que permite determinar cuán probable es identificar a un sujeto infectado o una persona sana según la presencia o ausencia de la infección, así como relacionar la sensibilidad y la especificidad de una prueba en un solo parámetro ${ }^{50}$. Asimismo, es importante incluir en los estudios futuros otros índices de valoración de pruebas diagnósticas que permitan complementar los datos aportados por los estudios ejecutados y establecer la utilidad diagnóstica de las pruebas evaluadas hasta la fecha. En este sentido, por ejemplo la proporción de resultados falsos complementa la información dada por la sensibilidad y la especificidad y hace referencia a la validez, pues define la proporción de individuos que estando infectados presentan un resultado negativo o estando sanos presentan un resultado positivo ${ }^{51}$. De la misma manera, la proporción de pacientes correctamente diagnosticados determina la eficiencia de la prueba, indicando la proporción de resultados válidos en el conjunto de resultados y la razón de odds diagnóstica establece la asociación entre el resultado de una prueba y la presencia de enfermedad (o infección), mientras que el índice J de Youden resume la validez de la prueba determinando la concordancia o la discrepancia entre los resultados, empleando los parámetros de sensibilidad y especificidad ${ }^{52}$.

Los artículos incluidos en la presente revisión sistemática y metanálisis incluyeron individuos con un amplio rango etario, población general, habitantes en zonas endémicas para estrongiloidiasis y pacientes inmunocomprometidos, lo que brinda mayor validez externa a los resultados presentados e implica que los hallazgos de validez, desempeño, rendimiento y efíciencia no están circunscritos a una población específica. 
Además, el metanálisis realizado en la presente investigación mostró una serie de ventajas frente a los estudios individuales, tales como: i) se logra presentar la evaluación diagnóstica completa, superando las limitaciones de los estudios disponibles de manera individual, los cuales se limitan a evaluar solo la validez; ii) se dispone de hallazgos con mayor validez interna y externa al utilizar métodos estadísticos más robustos, una población con mayor grado de generalización frente a los estudios individuales y sin sesgos potenciales de selección y de extracción de datos; iii) se genera información válida, reproducible, con menor costo y mayor grado de evidencia que los estudios individuales $^{34,35}$.

Entre las limitaciones de este estudio se debe indicar que no fue posible incluir los resultados de otras técnicas como las basadas en inmunoensayos (ELISA) o la biología molecular (PCR), test de aglutinación indirecta en partículas de gelatina GIAP, sedimentación espontánea, método de Katokatz, formalina-etil-acetato y Harada-mori debido a que en una exploración de estudios publicados sobre su evaluación diagnóstica se observó una gran variabilidad en los protocolos empleados por diversos investigadores con una misma técnica, lo que impedía su agrupación y comparación. Esto marca la pauta para investigaciones posteriores que realicen la evaluación diagnóstica completa de las técnicas aludidas. Además, es oportuno indicar que todos los Forest Plot del Meta-DiSc(es) son realizados bajo el modelo de efectos aleatorios, independientemente de los resultados de la prueba de homogeneidad, lo que implica que las estimaciones incluyen la variabilidad intra e inter-estudios, aún para los resultados que fueron homogéneos.

En conclusión, este metanálisis evidenció que los cuatro métodos de detección convencional de $S$. stercoralis pueden ser útiles para el diagnóstico de estrongiloidiasis, aunque los más idóneos por su mejor vali- dez, desempeño, eficiencia y rendimiento diagnósticos fueron el método de en placa de ágar y el método de Baermann para la separación de larvas.

\section{BIBLIOGRAFÍA}

1. Huggins D, Arruda CS, Medeiros LBd, Fragoso V. Estrongiloidíase Strongyloidiasis. Rev Bras Med.1990; 47:457-465.

2. Olsen A, van Lieshout L, Marti H, Polderman T, Polman K, Steinmann P, et al. Strongyloidiasis--the most neglected of the neglected tropical diseases? Trans R Soc Trop Med Hyg. 2009;103:967-72.

3. Schar F, Trostdorf U, Giardina F, Khieu V, Muth S, Marti H, et al. Strongyloides stercoralis: Global Distribution and Risk Factors. PLoS Negl Trop Dis. 2013;7:7.

4. Agrawal V, Agarwal T, Ghoshal UC. Intestinal strongyloidiasis: a diagnosis frequently missed in the tropics. Trans R Soc Trop Med Hyg. 2009;103:242-246

5. Siddiqui AA, Berk SL. Diagnosis of Strongyloides stercoralis infection. Clin Infect Dis. 2001;33:10401407.

6. Concha R, Harrington W Jr, Rogers AI. Intestinal strongyloidiasis: recognition, management, and determinants of outcome. J Clin Gastroenterol. 2005;39:203-211

7. Botero D, Restrepo M. Parasitosis humanas. 5ta ed. Medellín, Colombia: Corporación para investigaciones biológicas-CIB; 2012. p.162-74.

8. Montes M, Sawhney C, Barros N. Strongyloides stercoralis: there but not seen. Curr Opin Infect Dis. 2010;23:500-4.

9. Feely NM, Waghorn DJ, Dexter T, Gallen I, Chiodini P. Strongyloides stercoralis hyperinfection: Difficulties in diagnosis and treatment. Anaesthesia. 2010;65:298-301.

10. Corti M, Villafane MF, Trione N, Risso D, Abuin JC, Palmieri O. Infection due to Strongyloides stercoralis: epidemiological, clinical, diagnosis findings and outcome in 30 patients. Rev Chil Infectol. 2011;28:217-22.

11. Caumes E, Keystone JS. Acute strongyloidiasis: a rarity. Chronic strongyloidiasis: a time bomb! J Travel Med. 2011;18:71-2. 
12. Igual Adell R, Domínguez Márquez V. Estrongiloidiasis: epidemiología, manifestaciones clínicas y diagnóstico. Experiencia en una zona endémica: la comarca de La Safor (Valencia). Enferm Infecc microbiol Clín. 2007;25 Suplemento 2:38-44.

13. Keiser PB, Nutman TB. Strongyloides stercoralis in the Immunocompromised Population. Clin Microbiol Rev. 2004;17:208-17.

14. Marcos LA, Terashima A, Dupont HL, Gotuzzo E. Strongyloides hyperinfection syndrome: an emerging global infectious disease. Trans R Soc Trop Med Hyg. 2008;102:314-8.

15. Vadlamudi RS, Chi DS, Krishnaswamy G. Intestinal strongyloidiasis and hyperinfection syndrome. Clin Mol Allergy. 2006;4:8.

16. Sudré AP, Macedo HWd, Peralta RHS, Peralta JM. Diagnóstico da estrongiloidíase humana: importância e técnicas Diagnosis of human strongyloidiasis: needs and techniques. Rev Patol Trop.35:173-84.

17. Requena-Mendez A, Chiodini P, Bisoffi Z, Buonfrate D, Gotuzzo E, Munoz J. The laboratory diagnosis and follow up of strongyloidiasis: a systematic review. PLoS Negl Trop Dis. 2013;7:e2002.

18. Sato Y, Toma H, Takara M, Shiroma Y. Application of enzyme-linked immunosorbent assay for mass examination of strongyloidiasis in Okinawa, Japan. Inter J Parasitol.1990;20:1025-9.

19. Erdman DD. Clinical comparison of ethyl acetate and diethyl ether in the formalin-ether sedimentation. $\mathrm{J}$ Clin Microbiol. 198; 5:483-485

20. Brandelli CLC, Cargnin ST, Willers DMC, Oliveira KRP, Tasca T. Comparison between spontaneous sedimentation method and Paratest(registered trademark) for the diagnosis of intestinal parasitic infections. Trans R Soc Trop Med Hyg. 2011;105(10):604-606.

21. Becerril MA. Parasitología médica. 5ta ed. México, DF: McGraw Hill; 2011.

22. Mahdi NK, Setrak SK, Shiwaish SM. Diagnostic methods for intestinal parasites in southern Iraq with reference to Strongyloides stercoralis. Southeast Asian J Trop Med Public Health. 1993;24:685-91.

23. Knopp S, Mgeni AF, Khamis IS, Steinmann P, Stothard JR, Rollinson D, et al. Diagnosis of soil-transmitted helminths in the era of preventive chemotherapy: effect of multiple stool sampling and use of different diagnostic techniques. PLoS Negl Trop Dis. 2008;2:e331.
24. Hirata T, Nakamura H, Kinjo N, Hokama A, Kinjo $\mathrm{F}$, Yamane N, et al. Increased detection rate of Strongyloides stercoralis by repeated stool examinations using the agar plate culture method. Disponible en: http://www.ajtmh.org.

25. Sato Y, Takara M, Otsuru M. Detection of antibodies in strongyloidiasis by enzyme-linked immunosorbent assay (ELISA). Trans R Soc Trop Med Hyg. 1985;79:51-5.

26. Gonzaga HT, Ribeiro VS, Feliciano ND, Manhani MN, Silva DAO, Ueta MT, et al. IgG avidity in differential serodiagnosis of human strongyloidiasis active infection. Immunol Lett. 2011;139:87-92.

27. Schar F, Odermatt P, Khieu V, Panning M, Duong $\mathrm{S}$, Muth S, et al. Evaluation of real-time PCR for Strongyloides stercoralis and hookworm as diagnostic tool in asymptomatic schoolchildren in Cambodia. Act Trop. 2013;126:89-92.

28. Verweij JJ, Canales M, Polman K, Ziem J, Brienen EAT, Polderman AM, et al. Molecular diagnosis of Strongyloides stercoralis in faecal samples using realtime PCR. Trans R Soc Trop Med Hyg. 2009;103:3426.

29. Janwan P, Intapan PM, Thanchomnang T, Lulitanond V, Anamnart W, Maleewong W. Rapid detection of Opisthorchis viverrini and Strongyloides stercoralis in human fecal samples using a duplex real-time PCR and melting curve analysis. Disponible en: http://www.springerlink.com/content/69g66400q1584 71r/fulltext.html.

30. Van Der Feltz M, Slee PHTJ, Van Hees PAM, Tersmette M. Strongyloides stercoralis infection: How to diagnose best? Neth J Med. 1999;55:128-31.

31. Willcox HP, Coura JR. [A new design of the Baermann, Moraes, Coutinho's technique for the isolation of nematode larva]. Mem Inst Oswaldo Cruz. 1989;84:563-5.

32. Nielsen PB, Mojon M. Improved diagnosis of strongyloides stercoralis by seven consecutive stool specimens. Zentralbl Bakteriol Mikrobiol Hyg A. 1987;263:616-8.

33. Girard de Kaminsky R. Evaluation of three methods for laboratory diagnosis of Strongyloides stercoralis infection. J Parasitol. 1993;79:277-80.

34. Manterola C. Revisión Sistemática de la Literatura con Diferentes Tipos de Diseños. Int J Morphol [Internet]. 2009; 27:1179-86. 
35. Manterola C. Revisiones sistemáticas de la literatura. Qué se debe saber acerca de ellas. CIR ESP [Internet]. 2011; 91:149-55

36. Whiting PF, Rutjes AWS, Westwood ME, Mallett S, Deeks JJ, Reitsma JB, et al. QUADAS-2: A Revised Tool for the Quality Assessment of Diagnostic Accuracy Studies. Ann Intern Med. 2011;155:529-36.

37. Marchi Blatt J, Cantos GA. Evaluation of techniques for the diagnosis of Strongyloides stercoralis in human immunodeficiency virus (HIV) positive and HIV negative individuals in the city of Itajai, Brazil. Braz J Infect Dis. 2003;7:402-8.

38. Catarinella G, Monge E, León D, Núñez JA. Estrongiloidiasis en pacientes alcohólicos y métodos diagnósticos Strongyloidiasis in alcoholic patient and diagnostic methods. Rev Costarric Salud Public.1:146.

39. Glinz D, Silue KD, Knopp S, Lohourignon LK, Yao KP, Steinmann P, et al. Comparing diagnostic accuracy of Kato-Katz, Koga Agar Plate, Ether-Concentration, and FLOTAC for Schistosoma mansoni and Soil-transmitted helminths. PLoS Negl Trop Dis. 2010;4:e754.

40. Krolewiecki AJ, Lammie P, Jacobson J, Gabrielli AF, Levecke B, Socias E, et al. A public health response against Strongyloides stercoralis: time to look at soil-transmitted helminthiasis in full. PLoS Negl Trop Dis. 2013;7:e2165.

41. Kozubsky L. Consideraciones sobre la biología y el diagnóstico de Strongyloides stercoralis. Acta Bioquím Clín Latinoam [Internet]. 2004; 38:333-8 pp.

42. Hernández F. Strongyloides stercoralis: Un parásito subestimado. Parasitol dia. 2001; 25:40-49.

43. Fallas S. Strongyloides stercoralis: Una discusión sobre su diagnóstico coproparasitológico y su prevalencia en pacientes positivos por el virus de la inmunodeficiencia humana (VIH). Acta Méd Costarric [Internet]. $2000 ; 42$.

44. Cardona j, Bedoya K. Frecuencia de parásitos intestinales y evaluación de métodos para su diagnóstico en una comunidad marginal de Medellín, Colombia. Iatreia [Internet]. 2013; 26:257-68.

45. Anamnart W, Pattanawongsa A, Intapan PM, Maleewong W. Factors affecting recovery of Strongyloides stercoralis larvae: An approach to a newly modified formalin-ether concentration technique for diagnosis of strongyloidiasis. J Clin Microbiol. 2010;48:97-100.
46. Escrig-Sos J, Martínez-Ramos D, Manuel Miralles-Tena J. Pruebas diagnósticas: nociones básicas para su correcta interpretación $\mathrm{y}$ uso. Cir Esp. 2006;79:267-73.

47. Cerda J, Cifuentes L. Uso de tests diagnósticos en la práctica clínica (Parte 1): Análisis de las propiedades de un test diagnóstico. Rev Chil Infectol [Internet]. 2010 27:205-8

48. Medina Mc. Generalidades de las pruebas diagnósticas, y su utilidad en la toma de decisiones médicas. Rev Colomb Psiquiat [Internet]. 2011; 40.

49. Bermejo B. Epidemiología clínica aplicada a la toma de decisiones en medicina. Pamplona: Gobierno de Navarra; 2001.

50. Cifuentes L, Cerda J. Uso de tests diagnósticos en la práctica clínica (Parte 2): Aplicación clínica y utilidad de un test diagnóstico. Rev chil infectol. 2010; $27: 316-9$

51. Gutiérrez C, Ramos J. Evaluación de la validez de pruebas diagnósticas. CIMEL [Internet]. 2005; 10:6572.

52. Szklo M, Nieto FJ. Epidemiología intermedia: conceptos y aplicaciones. 2 ed. Madrid: Ediciones Diaz de Santos SA; 2003.

53. Figuera L, Ramírez E, Merchán E. Strongyloides stercoralis: Prevalencia y evaluación del diagnóstico utilizando cuatro métodos coproparasitológicos. Rev Soc Ven Microbiol. 2002;22:199-202.

54. Ribero Z, Chourio G, Díaz I, Padilla L, Zárate M, Ferrer J. Comparación de cuatro técnicas de laboratorio para el diagnóstico de estrongiloidiasis. Rev Soc Venez Microbiol. 2002; 22:68-73.

55. Lau Chong C, Samalvides Cuba F, Terashima Iwashita A. Evaluación de técnicas parasitológicas en el diagnóstico de estrongiloidiasis por Strongyloides stercoralis Efficacy of five methods for detection of Strongyloides stercoralis in human stool specimens. Rev Med Hered. 2005: 16:11-8.

56. Steinmann P, Zhou XN, Du ZW, Jiang JY, Wang LB, Wang XZ, et al. Occurrence of Strongyloides stercoralis in Yunnan Province, China, and comparison of diagnostic methods. PLoS Negl Trop Dis. 2007;1:e75.

57. Becker SL, Sieto B, Silue KD, Adjossan L, Kone S, Hatz C, et al. Diagnosis, clinical features, and self-reported morbidity of Strongyloides stercoralis and hookworm infection in a co-endemic setting. PLoS Negl Trop Dis. 2011;5: e1292. 
58. Ines EDJ, Souza JN, Santos RC, Souza ES, Santos FL, Silva MLS, et al. Efficacy of parasitological methods for the diagnosis of Strongyloides stercoralis and hookworm in faecal specimens. Acta Trop. 2011;120:206-10.

59. Khieu V, Schar F, Marti H, Sayasone S, Duong S, Muth S, et al. Diagnosis, Treatment and Risk Factors of Strongyloides stercoralis in Schoolchildren in Cambodia. PLoS Negl Trop Dis. 2013;7:e2035

60. Salazar SA, Gutierrez C, Berk SL. Value of the agar plate method for the diagnosis of intestinal strongyloidiasis. Diagn Microbiol Infect Dis. 1995;23:141-145.

61. Jongwutiwes S, Charoenkorn M, Sitthichareonchai P, Akaraborvorn P, Putaporntip C. Increased sensitivity of routine laboratory detection of Strongyloides stercoralis and hookworm by agar-plate culture. Trans R Soc Tropic Med Hy. 1999;93:398-400. 